\title{
Rural Residents' Endowment Willingness and Its Influencing Factors in Jilin Province
}

\author{
Lei li \\ Jilin agricultural university, college of humanities, Changchun130118, China \\ lilei@jlau.edu.cn
}

Keywords: rural residents; endowment willingness; influencing factors.

\begin{abstract}
The progress of human civilization, the development of economy, the improvement of medical technology and the follow-up effect of the family planning policy lead to the gradual increase of the endowment pressure in our country. In this paper, through the investigation of rural residents in three cities of Jilin Province in the form of a questionnaire, the current situation of their endowment willingness will be analyzed. In order to have a more thorough understanding of the influencing factors of the rural residents' endowment willingness choices, this paper adopts the binary logistic regression analysis, starting from the individual characteristics, family structure, social characteristics and so on, studies on the influences of these factors on their endowment willingness. Logistic model showed that gender and family structure have no significant influence on rural residents' endowment willingness; while age has significant effect on rural residents choosing government-endowment and self-endowment; in addition, profession also has very significant effect on the choice of self-endowment.
\end{abstract}

\section{Introduction}

The population structure of our country is undergoing a great change and the aging rate is much faster than that originally predicated. The aging problem has become a new problem that needs to be solved immediately. Nowadays, every day, there are 25,000 old people entering into the elder, and since the reform and opening up, there is a transition in the continuous declining trend of social burden coefficient. Population aging proposes a severe challenge of Chinese endowment security system. Handling the contradiction between rigid growth of endowment security level and economic development cycle fluctuations well has become an important challenge for China to deal with in the development [1]. In our country, in the elder population that has exceeded 200 million, there are more than $60 \%$ living in rural areas. In the trend of family miniaturization and surplus labor flow between rural and urban areas, the security function of family endowment mode is gradually weakened; self-endowment mode is struggling on the population aging and the aging; the community endowment model in economically developed areas does not have universal significance; rural social endowment insurance becomes stagnant because of historical and institutional reasons. Therefore, it is important to explore the influencing factors for rural residents' endowment willingness.

\section{Literature Review}

In foreign countries, the research on endowment willingness laid more emphasis on the analysis of the differences of the choice of residence places, and most of them will select factors for influencing endowment willingness from the social science and demography to analyze the differences. At present, the research on endowment willingness done by domestic scholars is mainly reflected in the groups that have different characteristics, such as: the elderly population, urban and rural residents, floating population, women groups and so on. Among them, the researches on the endowment willingness of the rural residents and the elderly population are relatively large, but the studies on the endowment willingness of the young people is quite few. Song Baoan did research on endowment willingness of elderly population, and he believed that the physical condition, place of residence, profession, education level and family harmony degree have certain influence on the endowment 
willingness of the old and define the endowment willingness into three kinds of endowment modes, namely living together mode, living alone and welfare mode [2].

\section{Survey on Rural Residents' Willingness to Care for the Elderly in Jilin Province}

\subsection{Data Sources and Sample Composition}

\section{(1)Data Sources}

The data comes from the survey of three cities in Jilin province. In order to make the data more scientific and reasonable, in the survey, three representative cities in Jilin Province are selected: the capital Changchun City, provincial city in Jilin City and key county-level city Dunhua City, and survey is done to the three cities. In the selection of the object, the survey, through the centralized payment and direct fill in the two ways, investigate of 19-60 years of rural residents in Jilin Province [3]. The survey issued a total of 451 questionnaires, and the effective recovery is 451 copies, thus the effective rate was $100 \%$.

\section{(2)Sample Composition}

From the perspective of gender, the number of men participating in the survey accounted for $44.8 \%$ of the total number and the number of women accounted for $55.2 \%$ of the total. The gender distribution is comparatively balanced.

In terms of age composition, people at $19-30$ years of age accounted for $15.1 \%$ of the total; people at $31-40$ years of age accounted for $20.4 \%$ of the total, people at $41-50$ years of age accounted for $33.5 \%$ of the total number, and people at 51-60 age of 31\% of the total number.

From the point of view of family structure, the backbone family of the three generation accounted for $22.6 \%$; core family of three people accounted for $56.8 \%$; joint family of a few generations accounted for $8.4 \%$; single parent family accounted for $5.8 \%$; one-man family accounted for $6.4 \%$.

Table 1 Investigation sample

\begin{tabular}{|c|c|c|c|c|}
\hline \multicolumn{2}{|c|}{ Variables } & Categories & Frequency(N) & Percentage $(\%)$ \\
\hline \multirow{3}{*}{ Effective } & \multirow{3}{*}{ Gender } & Male & 202 & 44.8 \\
\hline & & Female & 249 & 55.2 \\
\hline & & The total & 451 & 100 \\
\hline \multirow{5}{*}{ Effective } & \multirow{5}{*}{ Age } & 19-30 age & 68 & $15.1 \%$ \\
\hline & & $31-40$ age & 92 & $20.4 \%$ \\
\hline & & 41-50 age & 151 & $33.5 \%$ \\
\hline & & 51-60 age & 140 & $31 \%$ \\
\hline & & The total & 451 & 100 \\
\hline \multirow{6}{*}{ Effective } & \multirow{6}{*}{ Family structure } & $\begin{array}{l}\text { Backbone family of the three } \\
\text { generation }\end{array}$ & 102 & $22.6 \%$ \\
\hline & & Core family of three people & 256 & $56.8 \%$ \\
\hline & & $\begin{array}{l}\text { Joint family of a few } \\
\text { generations }\end{array}$ & 38 & $8.4 \%$ \\
\hline & & Single parent family & 26 & $5.8 \%$ \\
\hline & & One-man family & 29 & $6.4 \%$ \\
\hline & & The total & 451 & 100 \\
\hline \multirow{7}{*}{ Effective } & \multirow{7}{*}{ Professionals } & Students & 53 & $11.8 \%$ \\
\hline & & $\begin{array}{l}\text { Government-affiliated } \\
\text { institutions staffs }\end{array}$ & 13 & $2.9 \%$ \\
\hline & & enterprise staffs & 182 & $40.3 \%$ \\
\hline & & agricultural labor & 83 & $18.4 \%$ \\
\hline & & Others & 57 & $12.6 \%$ \\
\hline & & Unemployed persons & 63 & $14 \%$ \\
\hline & & The total & 451 & 100 \\
\hline
\end{tabular}




\subsection{Current Situation of Endowment Insurance in Jilin Province}

In February 2004, the general office of the State Council issued the Notice of Improving the Urban Social Security System Pilot Work in Jilin and Heilongjiang, and then Jilin Province has entered the old-age insurance pilot phase and the operation of the old-age insurance system for urban workers has embarked on a standardized track. After exploration and reform for ten years, urban workers' endowment insurance has achieved good results in coverage scope and income and expenditure. On January $1^{\text {st }}$, 2010, the promulgation of The Guiding Suggestion for Carrying out New Rural Social Endowment Insurance Pilot by the State Council presents the beginning of the new rural social endowment insurance pilot work in Jilin province [4].

By the end of 2013, the new agricultural insurance pilot and city home insurance pilot have been fully launched and achieved full coverage of the system. In July 2014, the $12^{\text {th }}$ Communist Party of Jilin Provincial Committee passed the Implementing Suggestion on the Establishment of a Unified Basic Old-age Insurance System for Urban and Rural Residents, Notice of Farmers Settled in the City Participate in Town Worker Basic Endowment Insurance Relevant Issues, and The Urban and Rural Old-age Insurance System of Jilin Province Convergence Approach (Provisional) three rural endowment insurance system ways, and fully implemented urban and rural old-age insurance system reform.

Table 2 Status of endowment insurance in Jilin Province from 2011 to 2013

\begin{tabular}{|c|c|c|c|c|}
\hline & & 2011 & 2012 & 2013 \\
\hline \multirow[t]{3}{*}{ Population(ten thousand) } & Urban workers & 617.5 & 632.2 & 655.2 \\
\hline & $\begin{array}{l}\text { Urban and rural } \\
\text { residents }\end{array}$ & $\begin{array}{l}\text { 389.5(New agricultural } \\
\text { insurance) }\end{array}$ & 561.3 & 643.1 \\
\hline & The total & 1007 & $\begin{array}{c}1193 . \\
5\end{array}$ & $\begin{array}{c}1298 . \\
3\end{array}$ \\
\hline \multirow[t]{3}{*}{ Fund income(a hundred million) } & Urban workers & 350.4 & 390.6 & 462.8 \\
\hline & $\begin{array}{l}\text { Urban and rural } \\
\text { residents }\end{array}$ & $\begin{array}{l}\text { 10.2(New agricultural } \\
\text { insurance) }\end{array}$ & 24.3 & 24.4 \\
\hline & The total & 360.6 & 414.9 & 487.2 \\
\hline \multirow[t]{3}{*}{ Fund expenditure(a hundred million) } & Urban workers & 308.1 & 377.6 & $44 S .2$ \\
\hline & $\begin{array}{l}\text { Urban and rural } \\
\text { residents }\end{array}$ & $\begin{array}{l}\text { 6.1(New agricultural } \\
\text { insurance) }\end{array}$ & 12.5 & 15 \\
\hline & The total & 314.2 & 390.1 & 463.2 \\
\hline \multirow[t]{3}{*}{$\begin{array}{c}\text { Accumulated balance(a hundred } \\
\text { million) }\end{array}$} & Urban workers & 394.1 & 407.1 & 421.6 \\
\hline & $\begin{array}{l}\text { Urban and rural } \\
\text { residents }\end{array}$ & $\begin{array}{l}\text { 5.6(New agricultural } \\
\text { insurance) }\end{array}$ & 20.6 & 30.1 \\
\hline & The total & 399.7 & 427.7 & 451.7 \\
\hline
\end{tabular}

\section{Analysis on the Influencing Factors for Rural Residents' Endowment Willingness}

There are many factors that affect the willingness of young people to care for the elderly, including individual characteristics, family factors, policy factors and so on. In order to fully grasp and explain the impact degree and direction of different factors, this article will analyze from the four aspects gender, age, and profession.

\subsection{Gender}

From the results of the regression, gender has no significant influence on the rural residents' willingness to care for the elderly, that is, the choice of the main body of the responsibility ( $\mathrm{P}>0.05)$. Whether choose government $(\mathrm{P}=0.817)$, themselves $(\mathrm{P}=0.051)$, children $(\mathrm{P}=0.176)$, endowment institutions $(=0.293$ respectively), relatives and neighbors $\mathrm{P}=0.335$ or community $(\mathrm{P}=0.583)$, gender has no significant effect on endowment willingness [5]. Additionally, due to the influence of social environment, living environment and so on, among contemporary youths, life outlook and value outlook of men and women are comparatively similar, and for young people, endowment for them is a distant thing that most people are not going to consider this issue. 
Table 3 Influence of gender on endowment willingness

\begin{tabular}{|c|c|c|}
\hline endowment willingness & & Gender \\
\hline Government & B & 0.044 \\
\hline & Sig. & 0.817 \\
\hline & Exp(B) & 1.045 \\
\hline Themselves (including the spouse) & B & 0.386 \\
\hline Children & Sig. & 0.051 \\
\hline & Exp(B) & 1.47 \\
\hline & B & -0.272 \\
\hline & Sig. & 0.176 \\
\hline Professional endowment institutions & Exp(B) & 0.762 \\
\hline & B & 0.216 \\
\hline & Sig. & 0.293 \\
\hline friends and relatives & Exp(B) & 1.241 \\
\hline & B & -0.629 \\
\hline & Sig. & 0.335 \\
\hline & Exp(B) & 0.533 \\
\hline & B & -0.222 \\
\hline & Sig. & 0.583 \\
\hline & Exp(B) & 0.801 \\
\hline
\end{tabular}

Table 4 Influence of age on endowment willingness

\begin{tabular}{|c|c|c|}
\hline endowment willingness & & Age \\
\hline Government & B & -0.051 \\
\hline & Sig. & 0.021 \\
\hline & Exp(B) & 0.95 \\
\hline Themselves (including the spouse) & B & 0.105 \\
\hline & Sig. & 0 \\
\hline Children & Exp(B) & 1.111 \\
\hline & B & 0.038 \\
\hline & Sig. & 0.103 \\
\hline & Exp(B) & 1.039 \\
\hline Professional endowment institutions & B & -0.018 \\
\hline & Sig. & 0.442 \\
\hline Friends and relatives & Exp(B) & 0.982 \\
\hline & B & -0.067 \\
\hline & Sig. & 0.359 \\
\hline All social sectors & Exp(B) & 0.935 \\
\hline & B & -0.013 \\
\hline & Sig. & 0.786 \\
\hline & Exp(B) & 0.987 \\
\hline
\end{tabular}

\subsection{Age}

Regression results show that age has significant effect on the choice of relying on government and themselves for endowment (including the spouse) $(\mathrm{P}<0.05)$, while the effect is not significant on the choice of the children, professional endowment institutions, friends and relatives and all social sectors for endowment. And from the B value, age is negatively related to the choice of government endowment, which represents that the older people are not willing to rely on the government to guarantee their elderly life [6]. Their careers and families has been basically stable and they have a certain economic strength, so they whose living standards is relative higher will not choose to depend on the government to guarantee their elder life. Significance of age on the selection of 
self-endowment is 0 , which shows that age has extremely significant influence on the choice of self-endowment.

\subsection{Profession}

Profession only has a significant impact on self-endowment willingness, and $\mathrm{P}$ value is 0.001 , which shows that the impact is very significant, while the influence is not significant on the choice of government, children, professional endowment institutions and other endowment willingness. The author believes that this is mainly because in this investigation, the rural residents who are above 30 years old are more than 50\% [7]. That is to say, more than half of the people already participate in the work and the people who have work will have certain economic income, and currently most working institutions in our country will pay endowment insurance for employees. Under the guarantee function of the certain economic basis and basic endowment insurance, they are more willing to choose self-endowment.

Table 5 Influence of profession on endowment willingness

\begin{tabular}{|c|c|c|}
\hline endowment willingness & Profession \\
\hline Government & B & -0.03 \\
\hline & Sig. & 0.184 \\
\hline & Exp(B) & 0.97 \\
\hline Themselves (including the spouse) & B & 0.078 \\
\hline & Sig. & 0.001 \\
\hline Children & Exp(B) & 1.081 \\
\hline & B & 0.019 \\
\hline & Sig. & 0.441 \\
\hline & Exp(B) & 1.019 \\
\hline Professional endowment institutions & B & 0.012 \\
\hline & Sig. & 0.625 \\
\hline Friends and relatives & Exp(B) & 1.102 \\
\hline & B & -0.017 \\
\hline & Sig. & 0.822 \\
\hline & Exp(B) & 0.983 \\
\hline & B & -0.027 \\
\hline & Sig. & 0.58 \\
\hline & Exp(B) & 0.973 \\
\hline
\end{tabular}

\section{Conclusion}

Most of the rural residents belong to the self-endowment, and the second is the social-endowment, and the least is the type of children-endowment. It can be seen that the old-age support of rural residents mainly relies on themselves and their spouses, and even living with their children, the vast majority of them still rely on themselves in the economy [8].

From the overall analysis of the results, only age and profession these two factors have a significant impact on the endowment willingness of rural residents. While gender and family structure have no significant impact on the endowment willingness. In addition, in the choice of endowment willingness, more rural residents hope to guarantee their old life through themselves (including the spouse). This fully shows that the concept of "Raise children to prevent from old age" has been gradually out of retirement concept, and at the same time it also reflects the differences with previous generations of contemporary people in the values, life style and behavior. It can be predicted that in the background of a large number of young rural labors transferring to urban, family living alone endowment model has been accepted by more and more rural residents. 


\section{References}

[1] Apostolakis G, Kraanen F, van Dijk G. Examining endowment beneficiaries’ willingness to pay for a socially responsible and impact investment portfolio: A case study in the Dutch health-care sector [J]. Journal of Behavioral and Experimental Finance, 2016.

[2] Rong-zhuo C, Hui-juan Y A N. The New Rural Social Endowment Insurance in the Eyes of Farmers: Awareness, Willingness and Evaluation-A Survey Based on 763 Farmers from 4 Counties of Hubei Province [J] [J]. Journal of Huazhong Agricultural University (Social Sciences Edition), 2013, 2: 010.

[3] Li D. Research on the Factors that Affect Female Farmers' Satisfaction Degree to the New Rural Endowment System: Based on the Evidence of Pingyuan in Guangdong[C]//Statistics \& Information Forum. 2013, 8: 019.

[4] Yi-yan X, Hong-luo W. Analysis of the endowment Willingness of Urban Residents and the Meet of Spiritual Needs: Cased by Fuzhou City [J]. Journal of Fujian Administration Institute, 2013, 2: 002.

[5] Venkatesh S, Vanishree M R. Awareness of endowment Schemes among unorganized Sector: An Empirical Study [J]. International Journal for Management and Behavioural Science, 2013: 2278-1285.

[6] YU L, LIAO C. The Study on endowment System Treatment Differences and Institutions for Old-age Care of Urban and Rural Residents [J]. Finance \& Trade Economics, 2015, 6: 013.

[7] Lue J D, Yeh C Y, Chang H W. The Adoption of the Fragmented National Endowment Insurance in Taiwan: A Historical Institutionalist Perspective [J]. Journal of Public Administration, 2013, 6: 003.

[8] Chen Z, Bengtsson T, Helgertz J. Labor Supply Responses to New Rural Social Endowment Insurance in China: A Regression Discontinuity Approach [J]. 2015. 